\title{
DAS PEDAGOGIAS DE GÊNERO À PERFORMATIZAÇÃO HETERONORMATIVA: NARRATIVAS SOBRE AS INFÂNCIA NA ESCOLA
}

\author{
FROM GENDER PEDAGOGIES TO HETERONORMATIVE PERFORMATIVITY: NARRATIVES: ABOUT \\ CHILDHOOD IN SCHOOL
} DE LAS PEDAGOGIAS DE GÉNERO A LA PERFORMATIZACIÓN HETERONORMATIVA: NARRATIVAS SOBRE
LAS INFANCIAS EN LA ESCUELA

\author{
JUNIOR, Eduardo Garralaga Melgar ${ }^{1}$ \\ CAETANO, Marcio ${ }^{2}$ \\ GOULART, Treyce Ellen ${ }^{3}$
}

\section{RESUMO}

O trabalho, fruto de entrevistas realizadas em uma escola assistencial de Ensino Fundamental na cidade de Pelotas - RS, em 2018, objetivou interrogar as pedagogias escolares e seus processos criativos considerando suas alianças e tensões junto ao sistema heteronormativo quando da educação de uma criança. Uma vez que que os gêneros refletem a força de "regimes de verdade", apuramos que, se por um lado, a performatividade da criança foi interpelada por regras que buscaram regulá-la e adequá-la a padrões que legitimavam a heterossexualidade enquanto expressão ideal para seu exercício, de outro, tais movimentos não ocorreram sem sua resistência e (re)criação.

Palavras-chave: Interdição. Acolhida. Heteronormatividade. Criança.

\section{ABSTRACT}

The work, as a result of interviews carried out at an elementary school in the city of Pelotas, RS, Brazil, in 2018, aimed to interrogate school pedagogies and their creative processes considering their alliances and tensions with the heteronormative system when educating a child. Considering that genders reflect the strength of "truth regimes", we find that if, on the one hand, the child's performativity was challenged by rules that seek to regulate it and adapt it to patterns that legitimize heterosexuality as an ideal expression for its exercise, on the other, such movements do not occur without their resistance and (re) creation.

Keywords: Interdiction. Welcomed. Heteronormativity. Child.

\section{RESUMEN}

El trabajo, fruto de entrevistas realizadas en una escuela asistencial de Enseñanza Fundamental en la ciudad de Pelotas-RS, en 2018, objetivó interrogar las pedagogías escolares y sus procesos creativos considerando sus alianzas y tensiones junto al sistema heteronormativo cuando la educación de la niñez. Considerando que los géneros reflejan la fuerza de "regímenes de verdad", constatamos que, si por un lado, la performatividad de la niñez fue interpelada por reglas que buscaron regularla y adecuarla a patrones que legitimaban la heterosexualidad como expresión ideal para su ejercicio, de otro, tales movimientos no ocurrieron sin su resistencia y (re) creación.

Palabras clave: Interdicción. Bienvenida. Heteronormatividad. Niñez.

\footnotetext{
1 Universidade Federal do Rio Grande - FURG- Rio Grande - Brasil

2 Universidade Federal do Rio Grande - FURG- Rio Grande - Brasil

3 Universidade Federal Fluminense- UFF-Rio de Janeiro - Brasil
} 


\section{INTRODUÇÃO}

Apresentamos, neste artigo, as narrativas de experiências protagonizadas por Eros, o pedagogo, e İbejì, a criança recém matriculada, em 2018, em uma escola assistencial de Ensino Fundamental na cidade de Pelotas- RS. Ao nos centrarmos na interação entre o docente e a criança, nossa intenção foi estabelecer um triplo movimento narrativo que contemplasse: a) os caminhos interpretativos produzidos pelo pedagogo para atribuir sentidos ao vivido na escola, b) o movimento de solidariedade proporcionado pela identificação entre o pedagogo e a criança e c) a narrativa do professor sobre İbejì, a criança que a escola ordenou cortar o cabelo e que adorava goiabas. Com esse interesse, objetivamos debater a escola e as pedagogias em seus movimentos de interdições e/ou as potencialidades para aquelas pessoas que, como İbejì e Eros, performatizam gêneros ininteligíveis dentro do sistema heteronormativo e heterosexista. Ao mesmo tempo, com as narrativas de Eros, mobilizadas por meio de entrevista aberta realizadas no primeiro semestre de 2018 , nos propomos a debater suas experiências dando conta de seus processos criativos.

İbeji tinha seis anos quando foi matriculada na escola em que atua Eros. Criança tímida e de pouca fala, evita fazer contato visual e nem se atreve a falar com as pessoas adultas. Parece entender que algo pode acontecer caso esteja sob seu olhar. Ela usa como tática estar sempre distante de sua observação e de suas ordens. No lugar de muitos gritos, crianças correndo e joelhos ralados, ìbejì permanece sem voz, quase todo o tempo. E quando sua voz solta de sua boca, quase sempre fechada, o ouvido que deseja saber de sua fala deve descer a sua altura. İbejì parece querer o silêncio, mesmo quando fala. Passa invisível essa criança!

Como ocorre rotineiramente nesta escola, o pedagogo entrevista individualmente as pessoas responsáveis pelas crianças nos meses iniciais do primeiro ano de seu ingresso e, ao longo do percurso escolar, busca acompanhar as famílias e o desenvolvimento cognitivo da criança. A escola, localizada na periferia da área central da cidade de Pelotas, é resultado de uma parceria entre uma entidade espírita e a prefeitura da cidade. Seu público é majoritariamente formado por crianças de camadas populares que vivem em moradias de madeiras, semelhantes às palafitas, as margens do canal São Gonçalo. No geral, elas são revestidas de latas de alumínio para evitar a entrada de fortes ventos, característicos do cordão litoral sul do estado e a friagem no inverno. Escondidas entre os armazéns, quase todos abandonados, da região do porto da cidade, as moradias produzem um visual colorido e, com o reflexo da iluminação fraca dos bairros pobres da cidade, acendem a região.

Eros, ao conhecer İbeji e ciente dos desafios que a interação com a criança the impunha, procurou o Nós do Sul: Laboratório de Estudos e Pesquisas Sobre Identidades, Currículos e Culturas, da Universidade Federal do Rio Grande-FURG e, a partir deste momento vem acompanhando as atividades do Grupo a fim de subsidiá-lo em suas ações nas escolas em que atua. A análise de sua narrativa ganha sentido quando possibilita, ao mesmo tempo, a reflexão sobre o seu processo de criação e a interpretação de fatos vividos ao longo de sua trajetória na escola. Sendo assim, ao trazer ao trabalho as narrativas de vida de Eros, estamos elegendo suas leituras dos fatos vividos e as consideramos como sendo a articulação entre as experiências individuais em interação com as 
dinâmicas coletivas da escola. Em outras palavras, ainda que a experiência seja conduzida em primeira pessoa, ela será fruto das interações com e no ambiente em que interage Eros. Como dito por Mafessoli (1987, p. 104): "O homem [e nós acrescentamos, a mulher] não é mais considerado isoladamente. E mesmo quando admitimos [...] não devemos esquecer que ele [e ela] resulta [m] de um corpo social e que, de retorno, volta a materializar-se nele [nela]."

Ao nos centrarmos em uma das dimensões da vida de Eros, avaliamos que seja primordial destacar que pensamos a vida não somente como ocorrências de fatos, mas, sobretudo, como experiências circunstanciadas. Adotar a trajetória de vida aliada à perspectiva cultural é, acima de tudo, concebê-la no interior das redes de significados apropriadas pela linguagem como integrante da realidade. Enquanto atribuidora de sentido às atividades cotidianas, a narrativa possibilita às pessoas envolvidas no ato de narrar (falar-escutar) posições interpretativas privilegiadas que doam sentido à existência. Aos/às participantes de sua leitura, ela convida à apropriação e experimentação daquilo que é invisibilizado no cotidiano em decorrência de sua contingência. Ao pensarmos nas práticas pedagógicas protagonizadas por Eros, mas facilmente traduzidas à várias outras pessoas em inúmeras outras escolas, a narrativa pode oportunizar a reflexividade e relatividade do sentido imediato atribuído à ação. Em uma perspectiva freiriana, isto significa "colocar em destacado" as questões diárias para refletir sobre elas, problematizando-as (FREIRE, 2013). Neste momento, um outro sentido, agora problematizado, é criado dando uma dimensão criativa à realidade e possibilitando a sua reelaboração continuamente.

\section{LEITURAS DA EXPERIÊNCIA: REGISTROS COTIDIANOS DA DOCÊNCIA}

Ao encontrar a mãe de İbeji, Eros revela a resistência que a criança possui em relação a estar dentro da escola. Para ìbejì, a adaptação foi muito mais do que conhecer e sentir-se pertencente a aquele espaço, um momento que era para ser de novas aprendizagens, de fazer novas amizades. Ao contrário, se constituiu, na narrativa de Eros, como um momento de resistência e de luta contra a escola. $\mathrm{Na}$ tentativa de entender a lógica que se operava na resistência de İbejì, sua mãe foi chamada à escola. Na leitura de Eros, algo parecia dissociar o seu entendimento sobre criança e o que projetava İbejì. Em suas brincadeiras, a criança parecia distante e deslocada do universo que se apresentava aos meninos e às meninas de sua idade. Quando deixada só e sem as ordens do pedagogo, a criança fugia para o pé de goiaba que ficava distante dos olhares vigilantes das pessoas adultas e que estava ao lado oposto daquele que era reservado aos brinquedos e brincadeiras. Chama-se a mãe de ìbeji, revela-se a estranheza escolar e, aos poucos, a mulher de pouca idade que a cria com auxílio da avó, vai revelando a Eros que sua resistência se inicia ainda na Educação Infantil:

Oyá, mãe de İbejì, disse que quando a criança completou três anos de idade foi matriculada na turma do maternal B de uma Escola de Educação Infantil, localizada em Pelotas. Era a primeira vez que estava imersa em um ambiente escolar institucionalizado. Durante a fase de adaptação, a mãe observava a rotina da escola e acompanhava a criança em todas as atividades que iam para a casa. Ela foi percebendo a forma como Ìbejì estava sendo disciplinada e os olhares que Ihe eram direcionados. 
As situações que desencadeavam essa atenção da coordenação e do serviço de assistência social, segundo o que disse Eros sobre a narrativa de Oyá, não estavam relacionadas a situações de indisciplina, conflito, bullying ou dificuldade de aprendizagem. A mãe relatou que havia observado que o modo como a criança falava, caminhava, brincava, se relacionava com colegas e professoras, despertou a atenção das/os profissionais da escola de origem. Nessa ocasião, o pedagogo também foi informado que a escola, por meio de sua equipe, elaborou e executou um plano pedagógico de intervenção centrado na criança e em sua família.

Desde os primeiros momentos em que estivemos com Eros, sua narrativa nos parecia afetada, ou seja, permeada de afetos referentes à história contada e seus sujeitos. Assim, nos permitiu conhecer seu olhar sobre si, a criança, a mãe e as demais personagens que circulavam o cotidiano escolar. Desse modo, nos apresentou também a angústia, a solidariedade e o não-lugar que o devir de İbejì ocupava no interior da pré-escola. Em uma trama de vulnerabilidades, sua mãe, por sua vez, não transferiu İbejì para outra escola porque dependia de um lugar que a acolhesse em turno integral já que ela estudava e cuidava de sua avó. Em Pelotas/RS, não há instituições públicas em turno integral para crianças em idade pré-escolar. Contudo, existem escolas assistenciais/filantrópicas - como era a escola anterior e atual de İbejì - que, em convênio com o município, absorve a demanda. Nesse sentido, a escola em que a criança estava matriculada, supria uma necessidade imediata da família.

O comportamento de İbejì, estava sob atenção por meio de "vigilâncias múltiplas e entrecruzadas" (FOUCAULT, 1996, p. 154) de toda a equipe de profissionais. Isso nos lembra Foucault quando nos ensina que a vigilância se estabelece como uma rede relacional "de alto a baixo, mas também até um certo ponto de baixo para cima e lateralmente; essa rede 'sustenta' o conjunto e o perpassa de efeitos de poder que se apoiam uns sobre os outros: fiscais perpetuamente fiscalizados." (FOUCAULT, 1996, p. 158). Ao mesmo tempo, a escola foi exercendo uma força coercitiva sobre a família. Analisando essas relações de poder em Foucault (1988), compreendemos que a instituição escolar exerceu essa força por meio das relações entre a família e os profissionais da escola. O poder, nesse sentido, sempre será desigual/móvel e, para a escola, foi uma estratégia exercida na tentativa de incidir sobre as subjetividades da criança, conforme Eros segue nos contando.

\begin{abstract}
Essa rede de vigilância criada sobre criança e família, foi despertando a atenção da mãe. İbejì não tinha um comportamento semelhante ao dos meninos em igual idade, destoava dos colegas. Não tinha seus trejeitos, modos de falar e caminhar e também não tinha interesse em brincadeiras e em nenhuma atividade pedagógica que fosse necessário realizar com seus colegas meninos, poucas as vezes que ela se sentia à vontade ao fazer alguma atividade com esses. Ao ir à escola, a responsável foi recomendada que mudasse as atitudes em relação à criança. Para a escola, ìbejì só agia como uma garota em decorrência da negligência da mãe, ela não lhe mostrava as coisas e atitudes que eram exclusivas dos meninos, nunca concepção heteronormativa de sentir, pensar e viver a vida, da infância a vida adulta.
\end{abstract}

Aqui, acreditamos, cabem algumas reflexões suscitadas pela leitura dos escritos de Goellner (2007), Foucault (1988) e Lima (2016) sobre a produção - cultural, intencional e atravessada por relações de poder do/sobre o corpo contemporâneo. Dessa forma, esses autores e autoras, de formas distintas, irão problematizar como os discursos foram sendo produzidos sobre os corpos e como 
também estes discursos produzem estes mesmos corpos em uma relação de retroalimentação constante.

Ao pensarmos o cenário escolar narrado por Eros e protagonizado por ìbejì e sua família, pensamos, com a contribuição dos Estudos Culturais, a lógica pedagógica de naturalização dos corpos. Com a narrativa de Eros a partir das contribuições dos Estudos Culturais, a questão desloca-se de uma lógica verdadeira e única e passa a existir em uma profusão de vozes que vão interpelando suas análises e questionamentos. A proposta de Goellner (2007), Foucault (1988), Lima (2016) versa que o corpo é provisório, conjuntural, histórico e desnatural. Também o são as falas produzidas $\mathrm{com} /$ por/sobre ele. Ao mesmo tempo, nos salienta que tais discursos são geradores de hierarquizações quando definem o que é positivo, belo, jovem e saudável. O que deve ser sentido e vivido na infância, na vida adulta e na velhice. Tais definições, conforme Foucault (1996), são atravessadas por relações de poder que buscam tornar estes corpos úteis, produtivos e docilizados. Estes atravessamentos, como podemos apreender na narrativa de Eros, se dão por meio de métodos disciplinares: "um conjunto de saberes e poderes que investiram no corpo e nele se instauraram" (p. 35). Estes métodos encontram-se balizados nos discursos produzidos pela ciência, pela escola e (re) produzidos pela sociedade, na tentativa de uniformizar o comportamento humano, buscando definir, a partir da genitália, um único modo de ser e estar no mundo.

Nestes termos, é importante considerarmos, quando pensamos os corpos que transitam pelo espaço escolar, os modos como a heteronormatividade enquanto "sistema político e epistemológico de governabilidade dos corpos e subjetividades" (CAETANO et al, 2017, p. 88) incide sobre os diferentes currículos e experiências na/com a escola. Assim, concordamos que as relações sociais de sexo se exercem de maneira transversal ao conjunto da sociedade, fazendo com que homens e mulheres sejam atravessados/as por elas. Tais interações são pautadas por hierarquizações e noções modernas/coloniais de complementariedade, por uma perspectiva que exige legibilidade social e (auto) verificação constantemente reiterada. Assim, tornam-se preceitos para a vida social. Conforme Lima,

[...] não é voluntariamente que assumimos um sexo e um gênero, mas, ao contrário, é a própria força da matriz de inteligibilidade sexual, a despeito de nossa vontade pessoal, que nos funda sujeitos por meio de uma designação de heterossexualidade compulsória. Em outras palavras, nosso corpo cobra sentido - inteligibilidade - na medida em que se ajusta às normas regulatórias da sexualidade; será por e na adequação aos ditames de tais normas que nossos corpos ganharão sentido e poderão ser lidos pela cultura. (2016, p. 196).

Ocorre que, na narrativa apresentada sobre İbejì, sua performance de gênero era completamente ininteligível ao destoar da norma esperada. Nesse cenário de tentativa de adequação às normas que sustentam o social colonial/moderno, tanto ìbeji quanto sua família parecem não colaborar na reiteração e encenação necessárias ao papel de gênero exigido.

İbejì tinha muitas bonecas. Algumas muito antigas, repassadas à sua mãe na infância e que agora era objeto de brincadeiras e imaginações de İbeji. Em um encontro realizado aqui na escola, a mãe relatou que quando chegava em casa, colocava uma roupa que simulasse um vestido e brincava de "mamãe" das bonecas, transformava seu quarto em uma casa de bonecas, 
fazia comidinhas para elas, cuidava delas conforme os cuidados que recebia de sua mãe e bisavó.

Dessa forma, a escola incita a mãe a exercer sobre a criança e sobre si, mesmo em casa, uma vigilância discreta que "[...] funciona permanentemente e em grande parte em silêncio" (FOUCAULT, 1996, p. 158). Tal abordagem nos remete à reflexão de que mesmo o que é considerado anormal, não está fora da norma. De fato, para esse/a sujeito/a serão direcionados esforços de disciplinamento e vigilância para que se adeque à normalidade (CAETANO, et al, 2017.). Nesse sentido, para que a norma se estabeleça como tal é necessário que todas dela participem e sejam vigias de si e de outrem. Porém, com todos os cuidados exigidos, os corpos teimam em transgredir e a transgressão, tão ameaçadora que exige correção imediata, muitas vezes está no detalhe, nas pequenas alterações possíveis realizadas pelos/nos corpos dos sujeitos desviantes.

Para a mãe, o comportamento de İbejì era tão natural. Era tão tranquilo que em nenhum momento havia desconfiado que algo pudesse estar errado. Oyá disse que İbejì nunca havia dito que era uma menina, ela se identificava como İbejì e pronto. Se não era menina muito menos dizia que era menino. Essa percepção de ser menino ou menina, havia sido instigada na outra escola, quando as professoras, a coordenação e a assistência social, a corrigiam para andar, agir e falar como um menino. Com todas as limitações na escola, Oyá disse que a casa se tornou o seu único refúgio, sobretudo seu quarto.

A passagem narrativa acima nos aproxima dos escritos de Welzer-Lang (2001) sobre a produção das masculinidades e das relações sociais de sexo. Para o autor, a fim de que um pequeno homem seja reconhecido como pertencente a esse gênero, ele deve afastar-se ao máximo de quaisquer semelhanças e afinidades com o universo construído socialmente como próprio das mulheres. A construção da masculinidade ocorreria em lugares monossexuados que construiriam o masculino de forma paradoxal, antagônica e complementar ao feminino. O autor chamou o conjunto de tais locais de "casa dos homens", ou seja, um lugar onde a homossociabilidade pode ser vivida e experimentada em grupos de pares. Nesses grupos, os mais velhos, aqueles que já foram iniciados por outros, mostram, corrigem e modelizam os que buscam o acesso à virilidade (WELZER-LANG, 2001, p. 482). O autor vai sublinhando os modos como a configuração das masculinidades está pautada em iniciações e mimetismos. Sobretudo, para ser homem, é necessário não se associar a uma mulher. Assim, para Welzer-Lang, o feminino é construído enquanto polo central de rejeição e inimigo que precisa ser combatido para que não se seja tratado como são as mulheres. Por conseguinte, a menor rasura nas fronteiras de gênero que se querem tão bem delimitadas leva à dúvida sobre a coerência entre sexogênero-orientação sexual.

A mãe, por recomendação da instituição escolar em que estava matriculada a criança no préescolar, sob ameaça de ser encaminhada ao conselho tutelar por negligência em relação à forma como a criança andava, agia e falava, acatou algumas recomendações, que culminaram no surgimento de atitudes agressivas na criança. A principal queixa de İbejì era de que ela não podia ser quem ela queria ser. Começou a ficar irritada com a escola e com a mãe, que não sabia como agir diante da pressão da escola, onde lbeji havia feito o pré-escolar. 
Britzman (1996) nos ajuda a pensar sobre essa cultura escolar, que coloca a heterossexualidade como algo "normal" e "natural" e que

[...] a mera menção da homossexualidade vá encorajar práticas homossexuais e vá fazer com que os/as jovens se juntem às comunidades gays e lésbicas. A ideia é que as informações e as pessoas que as transmitem agem com a finalidade de "recrutar" jovens inocentes [...]. Também faz parte desse complexo mito a ansiedade de que qualquer pessoa que ofereça representações gays e lésbicas em termos simpáticos será provavelmente acusada ou de ser gay ou de promover uma sexualidade fora-da-lei. Em ambos os casos, o conhecimento e as pessoas são considerados perigosos, predatórios e contagiosos. (p. 79-80).

Essa intervenção que foi sendo construída no cotidiano escolar e familiar de Ìbejì, de acordo com Britzman (1996), evidencia a concepção de que a homossexualidade, travestilidade e a transexualidade são passíveis de serem tratadas, revertidas com ações de controle do comportamento humano. Conforme Eros segue narrando, a escola continuava sua intervenção.

\begin{abstract}
Chegou ao ponto de a escola intervir diretamente na casa de Ìbejì. Em visita da equipe multidisciplinar da instituição, foi recomendado que a mãe e a avó, alterassem a cor do quarto: de lilás para azul. A mãe percebeu o quanto a troca da cor do quarto alterou a relação que o menino tinha com seu cantinho. As cortinas também foram trocadas e alguns brinquedos substituídos. Com todas essas mudanças, a criança tinha seu andar e seu vocabulário corrigido pela escola. A mãe relatou que, no trajeto até a escola, algumas quadras antes de chegar, ela mesma já corrigia o próprio caminhar, sempre resmungando com tristeza de que não "poderia caminhar como gostava". A mãe argumentava para a equipe técnica da instituição escolar, que não via o brincar como um estímulo para que a criança se tornasse homossexual. A escola defendia pra mãe que as crianças nascem meninas e meninos e que cabia ao pai e mãe a responsabilidade por aquilo que ela se tornaria no futuro. Quando Ìbeji dizia que não conseguia ser quem era, que caminhar de um jeito, falar e brincar de outro não representava o que queria ser, a mãe foi compreendendo que era muito mais complexo. Não era mudando a rotina, trocando os brinquedos, corrigindo o comportamento de Ìbejì que deixaria de ser ou se tornaria alguma coisa. Para a Oyá, İbejì era criança e estava sendo criança vivendo suas coisas e seu mundo.
\end{abstract}

A escola parecia tomar para si, enquanto instituição, a tarefa de enquadrar Ìbejì e sua família em moldes adequados à heteronormatividade. Em contrapartida, na narrativa docente, sua mãe parecia compreender aquilo que Butler (2003) nos falava, a partir dos escritos de Beauvoir, sobre as dimensões entre o sexo e o gênero. A estadunidense, ao debater as contribuições da feminista francesa, irá dizer-nos que sexo e gênero sempre foram sinônimos e igualmente elaborados na cultura. Nessa mesma direção, ao retornarmos aos escritos de Daniel Welzer-Lang, encontramos pistas que aproximam a percepção sobre as relações hierárquicas construídas entre gêneros binários e o conceito de LGBTfobia4.

Para Welzer-Lang (2001), a homofobia (e nós dizemos LGBTfobia) é referida como um modelo político de gestão de corpos e desejos. Em outras palavras, seria "a discriminação contra as pessoas que mostram, ou a quem se atribui, algumas qualidades (ou defeitos) atribuídos ao outro gênero" (WELZER-LANG, 2001, p. 465). Vamos ao encontro desta conceituação quando consideramos as

\footnotetext{
${ }^{4}$ Mesmo entendendo que ainda não encontramos um conceito que dê conta da complexidade que se estabelece em torno das redes de violências cotidianas vividas pela população de lésbicas, dada a disputa interna nos movimentos sociais que denunciam que o conceito "homofobia" apenas visibiliza as vivências violentas de homens gay, optamos por usar o termo LGBTfobia.
} 
contínuas intervenções sobre a performatividade de ìbejì. Para além de corroborarmos em ler na narrativa do docente a homossexualidade ou heterossexualidade da criança, parece-nos importante reconhecer tais práticas escolares enquanto discriminatórias e direcionadas à adequação ao sistema de coerência sexo-gênero-orientação sexual (reprojetada pela escola).

\begin{abstract}
Seus colegas de classe, começavam a mexer com ìbeji. Diziam que ela não gostava de coisas de menino, que só gostava das coisas das meninas e das brincadeiras delas, que era uma "bicha", despertando em İbeji animosidade. A criança [ìbeji] começava a se tornar agressiva com seus colegas, ao ponto de impor-se fisicamente para alguns. A mãe contou que começou a perceber que algo estava errado. $O$ ápice da intervenção, foi quando a equipe técnica da escola condicionou a matrícula de ìbejì ao atendimento de todas as deliberações para correção do comportamento da criança, inclusive que cortasse os cabelos. İbeji tinha o cabelo pela cintura, nunca havia cortado e o comprimento era motivo de alegria, felicidade e orgulho para criança. Segundo Oyá, İbeji usava o cabelo em suas brincadeiras e teatralizações, ele interpretava várias coisas, até cavalo (risos).
\end{abstract}

A noção hegemônica de androginia surgiu nos anos 1970 e pretendia desafiar a perspectiva dicotômica acerca dos sexos (MORAWSKI, 1990). Quando emergiu, o conceito sugeria a combinação de características femininas e masculinas sugerindo a eliminação do dualismo sexual. Na mesma década, o conceito de androginia é apropriado pelo campo da psicologia que iria se apropriar dele o pensando como a possibilidade de o sujeito ser ora compassivo e em outros momentos, assertivo. $\mathrm{O}$ ser masculino e feminino tomaria suas feições a depender das circunstâncias (BEM, 1981).

Nesta esteira, ainda implicava que o sujeito pudesse combinar as duas modalidades, entendidas como complementares em um único ato. Deste modo podia-se dizer que "um indivíduo andrógino dispunha, pois de um maior leque de comportamentos que the permitem ser autônomo, flexível e adaptado aos diversos contextos (BEM, 1981). Neste sentido, ela era definida como a capacidade de um sujeito mostrar características e comportamentos instrumentais ou tipicamente masculinos (como a independência, a assertividade, a liderança, etc.) e expressivos ou tipicamente femininos (como a sensibilidade ou a empatia), entendendo que os participantes que apresentavam esta capacidade para comportar-se "androgicamente" tendiam a ser psicologicamente mais saudáveis e desenvolviam um melhor (auto) conceito (EICHINGER, 2000; SHIFREN \& BAUSERMAN, 1996). No entanto, segundo Conceição Nogueira (2001, p. 14) esta noção revelou-se paradoxal:

\footnotetext{
[...] inconveniente e desapropriada para as perspectivas feministas [...]. A questão principal residia no facto de o modelo da androginia continuar a reconhecer os conceitos convencionais de feminilidade e masculinidade, retendo o dualismo clássico e a afirmação de algumas diferenças de gênero "reais", isto é, a existência de entidades reais e internas do ponto de vista psicológico [...]. Para além disso, as análises quantitativas realizadas indicavam que os valores de masculinidade eram os melhores prelimitares do comportamento andrógino, surgindo deste modo uma valorização do modelo da masculinidade.
}

Parece, ademais, que os sujeitos andróginos têm uma maior probabilidade de selecionar o comportamento apropriado aos requerimentos de cada situação, o que se tem levado a considerar a androginia como um bom indicador do ajuste social da criança para a idade adulta (HIROKAWA; YAMADA \& MIYATA, 2000). Por outra parte, se tem sugerido que o ajuste social está estreitamente 
relacionado com a possibilidade de dispor de um amplo repertório de comportamentos e a flexibilidade ou plasticidade que os sujeitos, sobretudo, na infância, permitem ao ajuste do gênero (CHISHOLM, 1983). Neste sentido, os benefícios que se tem atribuído ao jogo na infância estão mediados pela amplitude comportamental e pela possibilidade que oferecem as situações lúdicas de ensaiar comportamentos e estratégias que posteriormente se generalizaram em outras situações sociais mais heteronormativas.

Ao longo de seu desenvolvimento, através da diversidade de situações e comportamentos que se implica com seus iguais, a criança aprenderia nos jogos das relações de gênero, os comportamentos que ela significará como masculino ou feminino. Esta aprendizagem será essencial à vida adulta, à medida que, por meio dela, as crianças adquirem as ferramentas básicas para se relacionar com os e as demais de forma socialmente adequada aos valores androcêntricos e heteronormativos, tornando-se inteligíveis. Entretanto, esta moldura no corpo andrógino e infantil depende de vários fatores e, nas experiências de İbejì, resultaram em violências que tinham como interesse central os seus ajustes aos modelos hegemônicos de masculinidade infantil nos seus espaços/tempos.

Com isso, compreendemos que os corpos já nascem conspurcados pela cultura. Já se originam "cirurgiados" por tecnologias discursivas precisas que irão orientar e validar as formas adequadas e impróprias do gênero, conforme nos afirmou Berenice Bento (2006). Nesta lógica normalizada, não somos somente nós a determinarmos o gênero de nossos corpos, ele é configurado por meio dos diálogos com as tecnologias educativas e performativas que nos regulam. Nas palavras de Grigorowitschs e Santos (2008, p. 77):

\footnotetext{
A socialização constitui-se de uma série de processos interativos e formadores das identidades, nos quais as crianças tomam parte como atores, sendo reconhecidas como seres humanos "incompletos" que precisam ser socializados somente por adultos. A categoria gênero é uma das formas de distinção presente nos processos de socialização e fundamental para a formação das identidades de meninas e meninos, ao definir formas de jogar e de socializar, modelando masculinidades e feminilidades variadas.
}

É interessante ler - com as experiências narradas por Eros sobre os sujeitos dessa história - os mecanismos que irão converter leis sociais em leis incorporadas e como essas leis se constroem e se reproduzem nos significados de gênero e suas inter-relações com outras heterodesignações. Tais mecanismos estão inscritos nos corpos e essas estruturas criam disposições nos sujeitos. Estão marcados profundamente nas práticas sociais sem que pareça possível definir sua origem na história e naturalizados na cultura. Quando pensamos o corte do cabelo de İbejì, pensamos que a mutilação em seu corpo se opera na mesma lógica de intervir no corpo andrógino de modo a eliminar seus excessos e torná-lo inteligível. 


\title{
O QUE PODE UMA PEDAGOGIA CORPORIFICADA?
}

Quando İbeji ingressou, em 2018, no primeiro ano da escola regular em que Eros trabalha como pedagogo, ainda permanecia com vínculos com a pré-escola, participando de atividades no contra turno aos da aula do primeiro ano. Durante esse período, sua frequência não era regular. Aos poucos, a escola foi constatando que suas faltas estavam atreladas a sua relação emocional com esse ambiente. Mesmo através de uma equipe técnica, a nova escola não conseguia aproximar-se da criança. Durante o ano, com a participação da mãe, foram necessários muitos encontros para que até mesmo para a família fosse criado um ambiente de segurança e respeito às características de İbejì. As atitudes da escola de Ensino Fundamental não se centravam no futuro, como ocorria na Educação Infantil. Apreendemos que sua lógica buscava criar no presente as condições para İbejì sentir prazer naquele espaço. Lima (2016) nos ensina que ainda que todas e todos sejamos tocadas/os pela norma, ela incide diferentemente sobre os corpos. Nesse sentido, masculinidades não hegemônicas racializadas e efeminadas parecem, como nos negrita o autor, "flertar" com a morte. A escola tem muito a ver com isso visto que é também por meio das diferentes instituições que a LGBTfobia e o heterossexismo atualizam e articulam-se.

\begin{abstract}
Aqui em nossa escola, presenciamos alguns episódios de agressividade entre İbejì com outros estudantes. Além de se debater contra classes e brigar com alguns colegas, não escutava as orientações da equipe, que tentavam, com diálogo, acalmá-la. İbejì só parava com a chegada de sua mãe e por isso ela era imediatamente chamada. Diante dessas situações, aos poucos, a mãe foi contando como ocorreu toda essa intervenção que a família passou. $O$ relato foi acolhido e a escola passou a buscar compreender a relação de ìbeji com aquele local. Percebemos o medo que possuía em relação a equipe docente e a direção. Em casa, a mãe foi orientada a parar imediatamente essa intervenção e recomendada a buscar um auxílio técnico psicológico para ajudar a família e a criança a entender toda essa situação. A mãe começou a deixar İbeji livre para ser e agir como sentia-se à vontade e não estava mais impondo a ìbejì comportamentos considerados, até aquele momento, como "ideais" a um menino de sua idade. Por outro lado, o temperamento de İbeji continuava. Inúmeras foram as vezes em que a criança foi encaminhada à coordenação e orientação para conversar. Por mais que a escola buscasse junto à mãe desconstruir aquela resistência, ìbejì ficava com medo e não conseguia sair desse círculo de preocupação. Algumas vezes, quando esboçava alguma reação verbal dizia que a escola não iria deixá-la ser quem era e que iriam cortar novamente seu cabelo. Essa situação está em todas as falas de İbeji que registramos aqui. Durante uma crise, sua mãe foi chamada à escola, para ajudar a conter e conversar com a criança. Eu não sabia o que fazer, ver aquela criança chorando me produzia uma angústia descontrolada. Eu sofria junto com ela, eu me peguei chorando inúmeras vezes, o que fizeram com essa criança?
\end{abstract}

Toda a rede de complexidades que envolveu ìbejì apresenta-se enquanto um convite para que a escola discuta seus projetos e quais as concepções de gênero trazem seus currículos. Consideramos que a abordagem escolhida e a insistência junto à família e İbejì aponta para uma prática pedagógica que destoa das noções de gênero enraizadas na pré-escola frequentada anteriormente. Nesse sentido, para Louro (1997, p. 23), a importância de se discutir o conceito de gênero se afirma, porque

(...) obriga aquelas/es que o empregam a levar em consideração as distintas sociedades e os distintos momentos históricos de que estão tratando. Afasta-se de (ou se tem a intenção de afastar) proposições essencialistas sobre os gêneros; a ótica está dirigida para um processo, para uma construção, e não para algo que exista a priori. O conceito passa a exigir que se pense 
de modo plural, acentuando que os projetos e as representações sobre mulheres e homens são diversos.

Na direção de práticas pedagógicas outras, que abarquem a diferença enquanto potência e que reconheçam os desdobramentos da atuação violenta da norma sobre os corpos generificados, foi exatamente aquilo que atravessava o corpo de İbejì que foi utilizado como ponte para alcançá-la e convidá-la ao encantamento pela escola.

\begin{abstract}
Foi durante um desses encontros... a mãe relatou que havia construído uma casa da árvore na goiabeira do pátio, onde İbeji brincava e colhia as goiabas para comer. İbeji, ama goiabas! Observando, também havia percebido que, com frequência, passava o recreio sob a goiabeira que temos aqui na escola. Foi então que tive a ideia, me aproximei e ofereci ajuda para pegar algumas frutas que ficavam bem no alto, onde as mãos de İbejì não alcançavam. Quando desci, contei que a coordenação e orientação, assim como ela, amavam goiabas. Deu certo! ìbejì começou a trazer goiabas para presentear a equipe. A cada fruta entregue, abria um sorriso e dava um abraço, diferentemente do que ocorreu no início do ano. Acho que ìbejì começou a sentir que a escola é um espaço de acolhimento. Embora ainda resistente, melindrada com a instituição, começou a conversar.
\end{abstract}

A atitude da escola de educação infantil e de Eros parece-nos movimentar dois eixos interessantes. O primeiro nos aproxima dos debates apresentados por Hooks (2013) a respeito do erotismo e o processo pedagógico. A autora percorre algumas memórias escolares suas e percebe que, ao pensar em seus e suas professoras, dificilmente consegue lembrar-se de seus corpos. Da mesma forma, nos conta sobre a primeira vez em que lecionara e sentiu vontade de ir ao banheiro durante a aula. Ao pensar nisso, refletiu que, durante sua graduação, essa nunca fora uma questão... como se, de fato, ao entrar em aula, deixasse a extensão de seu corpo e suas fisiologias, do lado de fora. Tal lógica, para a autora, também se apresenta para as/os discentes.

$\mathrm{Na}$ formação inicial, é como se as licenciaturas e pedagogias, não considerassem as especificidades dos corpos que comporão esses espaços junto à/ao docente. Como se na prática, as turmas fossem compostas apenas por cabeças... pelo intelecto das crianças... sem fome, sem cheiros, sem raças (o que, em uma sociedade racializada, cuja hegemonia é a branquitude, significa idealizar uma sala repleta de crianças brancas), sem vontades e sem as marcas que temos discutido aqui. $O$ que Bell Hooks (2013) vai sinalizar com essas histórias é a relevância do erótico para a efetivação de uma pedagogia crítica. Nessa direção, ressalta que o erotismo não deve ser considerado apenas em sua dimensão sexual, mas sim enquanto força que impulsione nossos modos de viver em um estado de existência real. Dessa forma, seria possível transformar a consciência de si proporcionando, não somente aos/às estudantes, mas também a professoras/es, modos de conhecer-se melhor e viver plenamente no/com o mundo. O corpo, a alegria, o prazer com a vida e o gosto por goiabas não pode ser deixado de fora.

O outro ponto que chama nossa atenção e acreditamos tenha sido fundamental para o sucesso das estratégias para aproximar-se de İbejì foi a própria performance de gênero de Eros: o docente reconhece-se na escola como homossexual. Novamente, salientamos que não é de nosso interesse definir a sexualidade ou identidade de gênero de İbejì. Contudo, sublinhamos este aspecto como 
relevante porque sugere o estabelecimento de um pacto de solidariedade pautado exatamente na identificação, na diferença redimensionada por Eros e İbejì, ou seja: o borramento das expectativas de coerência entre sexo-gênero-orientação sexual.

\section{ALGUMAS CONSIDERAÇÕES}

A performatividade das crianças é transpassada por regras regulatórias que visam estabelecer sua função social e legitimar a heterossexualidade enquanto expressão ideal para seu exercício. Sendo assim, coadunamos com parte do pensamento de Butler (2003) e também questionamos a noção de "naturalidade" contida no processo do "vir a ser" criança. Compreendemos que a materialidade dos corpos é dada por estratégias discursivas que apresentam intencionalidades políticas curriculares expressivas na escola. Por outro lado, os discursos sociais institucionalizados pelos modos curriculares de produção dos sexos legislam sobre nossas vidas ao estabelecerem quais relações serão permitidas para serem efetivadas no contexto escolar e mais amplamente na sociedade. Nesse processo, as identidades que se engendram fora da lógica da heteronormatividade androcêntrica acabam relegadas ao âmbito das "incompatibilidades sociais" não se tornando inteligíveis para a ótica dominante e oficial dentro da lógica escolar.

A partir da atitude da escola de Educação Infantil narrada por Eros, consideramos que as verdades discursivas sobre as práticas sexuais consideradas como legítimas nos apontaram alguns modos como essa representação é produzida a partir de pressupostos hierárquicos, utilitários, excludentes e discriminatórios. Desta forma, inferimos que a subjetividade é, assim como os conceitos e verdades, uma produção histórica, socialmente construída e, portanto, poderá ser desconstruída, emergindo em diferentes repertórios para se pensar a condição humana. Finalizando com as palavras de Foucault (1980, p.51), em que "não se pode falar de qualquer coisa em qualquer época, não é fácil dizer alguma coisa nova, não basta abrir os olhos, prestar atenção ou tomar consciência, para que novos objetos se iluminem e, na superfície do solo, lancem sua primeira claridade". Arriscamo-nos a afirmar que, nesse contexto, a herança cultural presente nas relações de gênero reflete a força dos "regimes de verdade" na produção de identidades e subjetividades infantis. E é pela disseminação desses "valores culturais" que os infantis vão se constituindo, assumindo posições de sujeito nas relações sociais. Como apresentado aqui, pedagogias críticas também se apresentam nessa arena disputando e tensionando por outras possibilidades e arranjos. Dessa forma, questionando os "espaços" a serem ocupados pelo "eu" e pelo "outro". 


\section{REFERÊNCIAS}

1. BEM, S. Sex-role Inventory: professional manual. Palo Alto: CA Consulting Psychologist, 1981.

2. BENTO, B. A reinvenção do corpo: Sexualidade e gênero na experiência transexual. Rio de Janeiro: Garamond, 2006.

3. BRITZMAN, D. O que é essa coisa chamada amor: identidade homossexual, educação e currículo. Educação \& Realidade, 21(1), pp. 71-96, 1996.

4. BUTLER, J. Problemas de gênero: feminismo e subversão da identidade. Rio de Janeiro, Civilização Brasileira, 2003.

5. CAetano, M.; RodRigueS, A.; LIMA, C. H. L; Roseiro, S. Pajubeyrizes fechativas: modos bichas de trânsito na escola. InterMeio: revista do Programa de Pós-Graduação em Educação, 23(46), pp. 87-105, 2017.

6. CHISHOLM, J. Navajo infancy: an ethological study of child development. Nueva York: Aldine, 1983

7. EICHINGER, J. Job stress and satisfaction among special education teachers: effects of gender and social orientation. International Journal of Disability, 47(412), 2000.

8. FOUCAULT, M. Vigiar e punir: nascimento da prisão. 14. ed. Petrópolis: Vozes, $1996 .$.

9.

10

11. FREIRE, P. Pedagogia do oprimido. Rio de Janeiro: Paz e Terra, 2013.

12. GOELLNER, S. A produção cultural do corpo. In. Louro, G. et al (Org.). Corpo, Gênero e Sexualidade: um debate contemporâneo na educação. Petrópolis: Vozes, 2007. pp. 28-40

13. GRIGOROWITSCHS, T.; SANTOS, L. Gênero e Sexualidade: Mapeando as igualdades e as diferenças entre os sexos e suas relações com a educação. Revista Educação, Grandes Temas. São Paulo: Segmentos, pp. 35-39, 2008. 
14. HIROKAWA, K.; DOHI, I.; YAMADA, F.; MIYATA, Y. The effects of sex, self gender type, and partner"s gender type on interpersonal adjustment during a first encounter: androgynous and stereotypically couples. Japanese Psychological Research, (42) 2, pp. 102-111, 2000.

15. ; LOURO, G. L. Gênero, sexualidade e educação: uma perspectiva pós-estruturalista. Petrópolis: Vozes, 1997.

LIMA, C. H. L. Linguagens pajubeyras: re(ex)sistência cultural e subversão da heteronormatividade. 2016. 265f. Tese (Doutoramento em Estudos Culturais), UFBA, Bahia.

MAFESSOLI, M. O tempo das tribos. Rio de Janeiro: Forense-Universitária, 1987.

MORAWSKI, J. Toward the unimagined: feminism and epistemology in psychology. In HareMustin, R.; Marecek, J. (Eds.), Making Difference. Psychology and the construction of gender. New Hawen, CT: Yale University Press, 1990. Sociedade: Revista da Associação Brasileira de Psicologia Social. 13(1), pp. 107-128, 2001. expressive traits, health behaviors, and perceived physical health. Sex roles, 34(11-12), pp. 841864, 1996. olhares na pesquisa em educação. Porto alegre: Mediação, 1996. pp. 23-38.

WELZER-LANG, D. A construção do masculino: dominação das mulheres e homofobia. Estudos Feministas, 9(2), 2001. pp. 460-482.

\section{Eduardo Garralaga Melgar Junior}

Doutorando no Programa de Pós-Graduação em Educação em Ciências: Química da Vida e Saúde da Universidade Federal do Rio Grande - FURG - Brasil- e membro do Nós do Sul - Laboratório de Estudos e Pesquisas sobre Identidades, Currículos e Culturas. Graduado em Pedagogia (2010) e Mestre em Educação pela Universidade Federal do Pampa (2014). Atualmente é orientador educacional na Prefeitura Municipal de Pelotas/RS.

\section{Marcio Caetano}

Pós-doutorando no PROPED-UERJ (PNPD-CAPES), doutor em Educação pela UFF, Líder do Nós do Sul: Laboratório de Estudos e Pesquisas sobre Identidades, Currículos e Culturas, Professor no 
Instituto de Educação da Universidade Federal do Rio Grande - FURG. Universidade Federal do Rio Grande - FURG-Brasil.

\section{Treyce Ellen Goulart}

Doutoranda no Programa de Pós-Graduação em Educação da Universidade Federal Fluminense, Mestra em Educação pelo Programa de Pós-Graduação em Educação (PPGEDU) da Universidade Federal do Rio Grande - FURG (2014-2016), formada pela mesma Instituição em História Bacharelado (2010). É membro do Nós do Sul Laboratório de Estudos e Pesquisas sobre Identidades, Currículos e Culturas e possui área de pesquisa e interesse no estudo de Relações Étnico-raciais, Interseccionalidade de Gênero, Raça e Classe, Feminismos das mulheres negras, Decolonialidade e Intelectualidade Negra.

\section{Como citar este documento}

MELGAR JUNIOR, Eduardo Garralaga; CAETANO, Marcio; GOULART, Treyce Ellen. Das Pedagogias de Gênero à Performatização Heteronormativa: narrativas sobre as Infância na escola. Reflexão e Ação, Santa Cruz do Sul, v. 28, n. 1, jan. 2020. ISSN 1982-9949. Disponível em: <https://online.unisc.br/seer/index.php/reflex/article/view/12332>. Acesso em: doi:https://doi.org/10.17058/rea.v28i1.12332. 